\title{
Prognostic Value of Viremia in Patients with Long-Standing Human Immunodeficiency Virus Infection
}

\author{
Annick Galetto-Lacour, * Sabine Yerly, \\ Thomas V. Perneger, Christophe Baumberger, \\ Bernard Hirschel, Luc Perrin, \\ and the Swiss HIV Cohort Study Group ${ }^{\dagger}$
}

\author{
Division of Infectious Diseases, Central Laboratory of Virology, and \\ AIDS Center, Institute of Social and Preventive Medicine, Geneva \\ University Hospital, Geneva, Switzerland
}

\begin{abstract}
Human immunodeficiency virus (HIV) viremia was evaluated in 73 patients with long-standing infection to investigate its relationship with clinical or biologic parameters and to assess its use as a predictor of clinical progression and death. After adjustment for other parameters, baseline HIV RNA level was significantly associated with baseline clinical stage and CD4 cell count. During follow-up (mean, 14.6 months), 16 patients died; 34 others had clinical progression of disease. In multivariate analysis, mortality was better predicted by baseline CD4 cell count (relative hazard [RH] for 100-cell decrease, 3.5; 95\% confidence interval [CI], $1.5-8.2 ; P=.003$ ) than by HIV RNA $(P=.28)$ or clinical stage. HIV RNA level was the best predictor of clinical progression (RH for 1 $\log$ increase, $2.8 ; 95 \% \mathrm{CI}, 1.6-4.9 ; P<.001$ ). Monitoring of HIV RNA level may help to identify patients who might benefit from antiretroviral or prophylactic therapy.
\end{abstract}

Human immunodeficiency virus (HIV) disease progression varies considerably among individuals, and treatment of HIVinfected patients is guided by clinical and laboratory indicators of disease activity. For instance, CD4 cell count is used to guide therapeutic decisions $[1,2]$ and to define HIV infection stage, including the onset of AIDS. A number of other clinical and laboratory markers have been used to estimate prognosis of HIV-infected patients [3, 4], but all have limitations in sensitivity, specificity, or predictive value.

Recent studies on the turnover of viremia and of CD4 cell counts have underscored interindividual differences that do not simply reflect HIV disease stages $[5,6]$. In addition, increases in CD4 cells after antiviral treatment do not always reflect clinical benefit [7].

HIV viremia levels presumably reflect HIV load more directly than do CD4 cell counts and may provide useful prognostic information. Cross-sectional studies have shown correlations between viremia and stage of HIV disease or seroimmunologic parameters, such as CD4 cell counts and neopterin and $\beta_{2}$-microglobulin levels [8-10]. However, more studies are needed to explore the potential predictive value of viremia for clinical progression or death. Thus, we prospectively assessed the use of HIV RNA level to predict clinical

Received 24 October 1995; revised 6 February 1996.

All subjects gave informed consent.

Financial support: National AIDS Research Program, Swiss Federal Office of Public Health; Swiss National Science Foundation (grants 32-32609.91, 3236065.92).

Reprints or correspondence: Dr. Luc Perrin, Central Laboratory of Virology, Geneva University Cantonal Hospital, 1211 Geneva 14, Switzerland.

* Present affiliation: Department of Pediatrics, Geneva University Cantonal Hospital.

${ }^{\dagger}$ Study group members follow text.

The Journal of Infectious Diseases 1996; 173:1388-93 (C) 1996 by The University of Chicago. All rights reserved 0022-1899/96/7306-0011\$01.00 progression of HIV disease and death in a group of patients infected with HIV for 7-11 years.

\section{Methods}

Study design. This prospective study evaluated the prognostic significance of HIV RNA level with regard to clinical progression and death. A cross-sectional analysis was done to identify variables associated with HIV RNA levels at baseline, because such variables could confound longitudinal associations between HIV RNA levels and disease progression.

Patient enrollment and follow-up. Patients followed in the Geneva AIDS Center and known to have contracted HIV before 1 January 1986 were eligible for this study. All were participants in the Swiss HIV Cohort Study, which includes an estimated $70 \%$ of Swiss AIDS patients and one-third to one-half of all HIVinfected persons in Switzerland [11]. Patients were enrolled between November 1992 and July 1993 at a regular follow-up visit. Of 114 potentially eligible patients, 74 agreed to participate and completed the baseline assessment. One patient was later lost to follow-up; the other 73 are included in this report. Follow-up was terminated 30 September 1994.

Outcome variables. The two outcome variables were clinical progression of HIV infection (minor opportunistic infections, AIDS-defining events, or HIV-related death [12]) and death of any cause. Dates of events, exact diagnosis of new opportunistic infections, and cause of death was obtained from the patient's attending physician.

Main predictor variable. The principal predictor variable was the number of HIV RNA copies measured at baseline by quantitative polymerase chain reaction. HIV RNA level was quantitated in relation to an external standard [13]. In brief, total RNA was purified from $50 \mu \mathrm{L}$ of serum using the guanidium thiocyanatephenol-chloroform method. Total RNA was reverse transcribed, and a 122-bp sequence (HIVHXB2: 4142-4264) of a conserved region of the pol gene was amplified. HIV RNA levels were expressed as the logarithm of RNA copies per milliliter of serum. 
Potential confounders. Variables evaluated as confounding factors included age, clinical stage of HIV disease, CD4 and CD8 cell counts, CD4:CD8 ratios, p24 antigenemia, $\beta_{2}$-microglobulinemia, and antiviral and prophylactic treatments at baseline (no data were available for changes of treatment over time).

Cross-sectional analysis. Potential confounders were first assessed for independent association with $\log$ (HIV RNA), and only those that fulfilled this condition were retained for further evaluation. These associations were explored using scatter plots for continuous variables and box plots for categorical variables. Linear regression analysis of variance models was selected on the basis of the exploratory analysis. A multivariate regression analysis identified variables associated independently with HIV RNA.

Prospective analysis. HIV RNA values (in log copies per milliliter) were divided into tertiles. In univariate analysis, incidence rates of disease progression and mortality rates (events per person-years of follow-up) were computed for each tertile. Tertiles of HIV RNA were compared using KaplanMeier analysis and $\log$ rank tests for linear trend [14]. HIV RNA level was also modeled as a continuous variable in proportional hazards models (hazard ratios were expressed for an increase of 1 unit in $\log$ HIV RNA). Proportional hazards models were used for potential confounders identified in the crosssectional analysis. $P<.05$ was considered statistically significant. Data were analyzed by statistical software (SPSS for Windows; SPSS, Chicago).

\section{Results}

Baseline characteristics. Of the 73 participants, $54(74 \%)$ were men. Average age was 35 years (range, 27-52). Main risk factors for HIV infection were intravenous drug use, 48 $(66 \%)$; homosexual contact, $15(21 \%)$; and other or unknown, $10(13 \%)$. At the baseline visit, subjects had been HIV-positive an average of 9 years (range, $7-11) ; 42$ patients $(58 \%)$ had received antiretroviral treatment; and $37(51 \%)$ received Pneumocystis carinii pneumonia prophylaxis. Twenty-two patients $(30 \%)$ were $\mathrm{CDC}$ stage A, $31(42 \%)$ were stage $\mathrm{B}$, and $20(27 \%)$ were stage $C$ [13]. The mean ( \pm SD) CD4 cell count was $277 \pm 249 / \mathrm{mm}^{3}$. Twelve patients $(16 \%)$ were category $1\left(\geqslant 500 / \mathrm{mm}^{3}\right), 27(37 \%)$ were category $2\left(200-499 / \mathrm{mm}^{3}\right)$, and $34(47 \%)$ were category $3\left(0-199 / \mathrm{mm}^{3}\right)$. Overall, 37 patients $(51 \%)$ had AIDS at baseline [13]. Mean ( \pm SD) HIV RNA was $5.28 \pm 0.90 \log \operatorname{copies} / \mathrm{mL}$. Tertiles were $2.49-$ 4.91 (lowest), 4.94-5.74 (middle), and 5.75-6.97 log copies/ $\mathrm{mL}$ (highest).

Relation of HIV RNA levels to baseline parameters. Baseline HIV RNA levels were similar in men and women $(5.25$ \pm 0.85 vs. $5.36 \pm 0.98 \log$ copies $/ \mathrm{mL} ; P=.24$ ) and in intravenous drug users and male homosexuals (5.23 \pm 0.89 vs. 5.50 $\pm 0.94 \log$ copies $/ \mathrm{mL} ; P=.32$ ). No association was observed between HIV RNA level and age (Pearson's $r=.07, P=.58$ ). HIV RNA level was inversely correlated with CD4 cell count in patients with $<500 \mathrm{CD} 4$ cells $/ \mathrm{mm}^{3}$, but there was no clear association between HIV RNA level and CD4 cell count if the latter exceeded $500 / \mathrm{mm}^{3}$ (figure 1). HIV RNA level was inversely correlated with CD8 cell count and was positively associated with levels of plasma $\beta_{2}$-microglobulin and p24 antigen (table 1). Association with CD4:CD8 cell ratios ap-
Figure 1. Scatter plot with Lowe's regression of $\log$ HIV RNA level by CD4 cell counts of 73 patients with long-standing HIV infection (dashed line indicates $>500$ CD4 cells $/ \mathrm{mm}^{3}$ ).

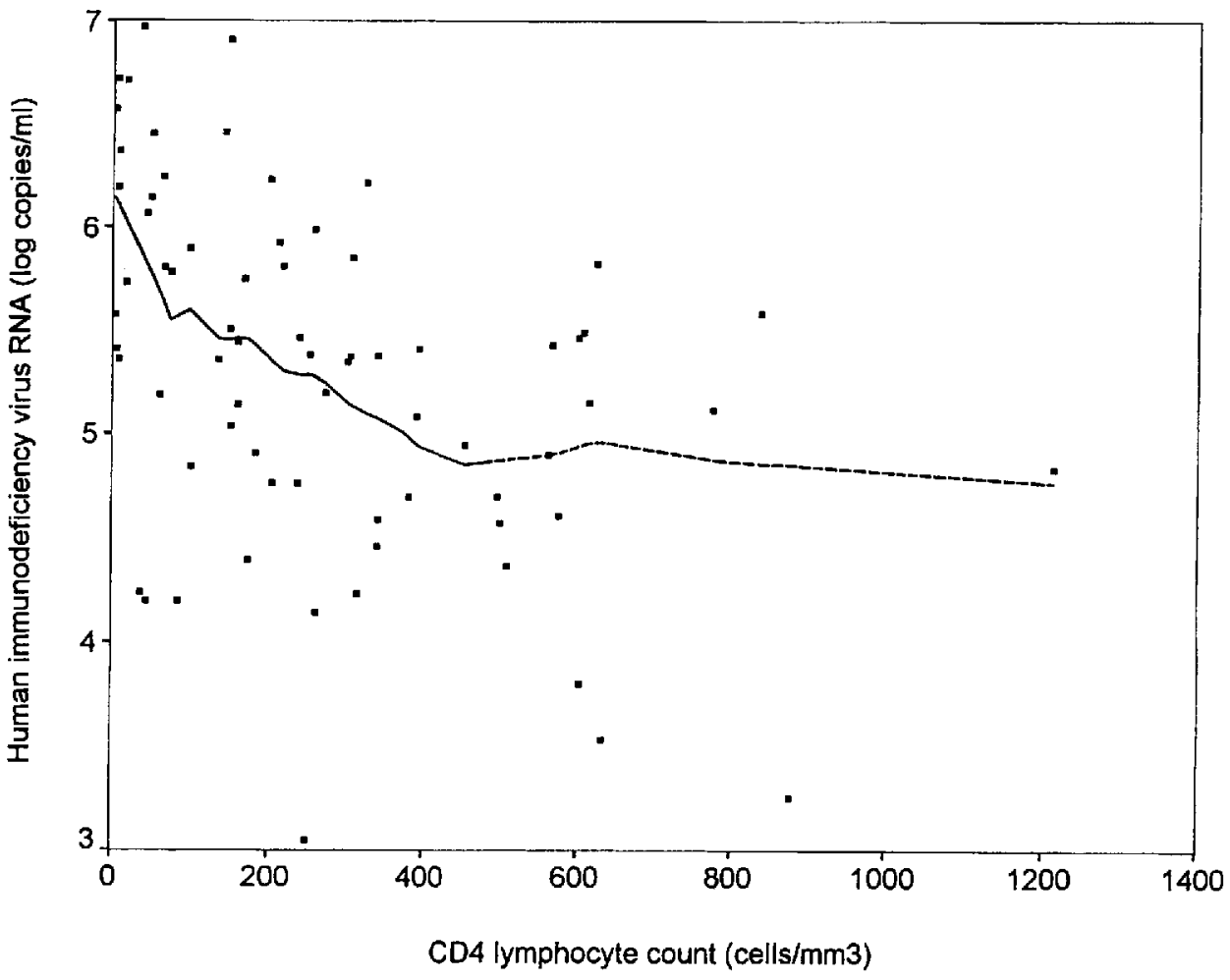


Table 1. Univariate associations between HIV RNA level and parameters of disease progression in 73 patients with long-standing HIV infection.

\begin{tabular}{lrlc}
\hline Variable & Slope & In log HIV RNA $/ \mathrm{mL}$ per & $P$ \\
\hline CD4 cell counts & & & \\
$\quad \leqslant 500$ & -0.25 & $100 \mathrm{CD} 4$ cells $/ \mathrm{mm}^{3}$ & $<.001$ \\
$\quad>500$ & 0.04 & & .73 \\
CD8 cell count & -0.72 & $1000 \mathrm{CD} 8 \mathrm{cells} / \mathrm{mm}^{3}$ & $<.001$ \\
CD4:CD8 cell ratios & & & \\
$\quad \leqslant 0.4$ & -0.24 & 0.1 ratio units & .003 \\
$>0.4$ & 0.01 & & .88 \\
$\beta_{2}$-microglobulin & 0.27 & $100 \mathrm{mg} / \mathrm{L}$ & .004 \\
p24 antigen & 0.10 & $10 \mathrm{ng} / \mathrm{L}$ & .002 \\
\hline
\end{tabular}

peared to be strongly negative for the lowest values $(<0.4)$, but no meaningful association was seen for higher values. HIV RNA level varied considerably within each clinical stage of HIV infection. Differences in mean values were statistically significant between stages $\mathrm{A}$ and $\mathrm{B}(4.60 \pm 0.92$ vs. $5.52 \pm$ $0.75 \log$ copies $/ \mathrm{mL}, P<.001)$ and stages $\mathrm{A}$ and $\mathrm{C}(4.60 \pm$ 0.92 vs. $5.65 \pm 0.70 \log$ copies $/ \mathrm{mL}, P<.001)$ but not between stages $\mathrm{B}$ and $\mathrm{C}(P=.56)$.

In multivariate models, HIV RNA level remained independently associated only with clinical stage $(P=.005)$ and CD4 cell count $(P=.05)$, while CD8 cell counts, CD4:CD8 cell ratios, and $\beta_{2}$-microglobulin and p24 antigen levels were no longer significantly associated with HIV RNA levels.

Mortality. Sixteen patients died during follow-up (mean, 444 days; range, 11-705). Fourteen deaths were HIV related, and 2 were suicides. The overall mortality rate was 0.18 per person-year. Mortality rates were $0.07,0.16$, and 0.32 by increasing HIV RNA tertile. The Kaplan-Meier analysis showed that survival was similar in patient groups defined by HIV RNA tertiles for the first 6-9 months of follow-up. These groups only diverged in survival later (figure $2 \mathrm{~A}$; log rank test for linear trend, $P=.02$ ). Results were similar when the 2 suicides were treated as nonevents (i.e., censored; data not shown).

In univariate proportional hazards models, clinical stage and CD4 cell count were better predictors of death than was HIV RNA level (table 2). When HIV RNA, CD4 cell counts, and clinical stages were included as covariates in the same model, CD4 cell counts remained a strong, statistically significant predictor of death, while the predictive values of HIV RNA level and clinical stages were no longer statistically significant. This result was observed both when HIV RNA level was categorized into tertiles and when it was analyzed as a continuous variable. In the latter analysis, the relative hazard of death was $2.8(95 \%$ confidence interval $[\mathrm{CI}], 1.4-5.6 ; P=.003)$ per $1 \log$ increase in univariate models and $1.5(95 \% \mathrm{CI}, 0.7-3.0 ; P=.28)$ after adjustment for CD4 cell counts and clinical stages.

Clinical progression. During follow-up, 34 patients (47\%) had 28 new opportunistic infections over an average of 345 days at risk: esophageal candidiasis and Candida stomatitis (4 each); bacterial pneumonia, weight loss, generalized herpes zoster, or other opportunistic infections (3 each); cryptosporidiosis (2); and cytomegalovirus retinitis, oral leukoplakia, cerebral toxoplasmosis, $P$. carinii pneumonia, chronic diarrhea, and atypical mycobacterial infection (1 each). Eight patients died without developing a new opportunistic infection: 6 of HIVrelated diseases that were considered to be clinical progression and 2 by suicide. The latter 2 were censored at the time of death for analysis of disease progression. The overall incidence rate of clinical progression was 0.49 events per person-year. Incidence rates were $0.20,0.36$, and 1.22 events per personyear by increasing HIV RNA tertile. Kaplan-Meier analysis showed striking differences in the rates of progression between patients in the highest HIV RNA tertile and the 2 other groups (figure 2B; $\log$ rank test for linear trend, $P<.001$ ).

In contrast to the analysis of mortality results, Cox modeling of the hazard of clinical progression identified baseline HIV RNA level as the best predictor (table 3). HIV RNA level was a strong predictor of clinical progression in all models, whereas CD4 cell counts were statistically significant predictors only in univariate analysis and became nonsignificant in models adjusted for HIV RNA level and clinical stage. The clinical stage at baseline did not predict well the incidence of clinical progression. The risk of clinical progression was increased almost 2 -fold in the middle HIV RNA tertile relative to the lowest tertile and $\sim 6$-fold in the highest tertile. In multivariate analysis, treatment at baseline (antiviral and prophylaxis of opportunistic infections) did not confound the association between viremia and clinical progression. When HIV RNA level was analyzed as a continuous variable, the relative hazard of clinical progression was $2.8(95 \% \mathrm{CI}, 1.7-4.5 ; P<.001)$ per $1 \mathrm{log}$ increase in univariate analysis and $2.8(95 \% \mathrm{CI}, 1.6-$ $4.9 ; P<.001)$ in multivariate analysis. Repetition of the analysis after exclusion of minor opportunistic infections provided similar results, although with a larger $\mathrm{CI}$ due to the smaller number of events (data not shown).

\section{Discussion}

Results of this prospective study suggest that HIV RNA level is a strong independent predictor of clinical progression in patients with long-standing HIV infection. In contrast, HIV RNA levels did not predict death independently: Death was best predicted by CD4 cell count. These results indicate that assessment of HIV RNA level might be a useful tool in the clinical management of HIV-infected patients.

Patients with HIV RNA levels $>5.75 \log$ copies $/ \mathrm{mL}$ had $\sim 1.22$ opportunistic infections per person-year. Such a risk level may justify close clinical surveillance, prophylaxis against opportunistic infections, and aggressive antiviral treatment directed against HIV, regardless of CD4 cell count. In this respect, among the 24 patients with HIV RNA level $\geqslant 5.75 \mathrm{log}$ copies $/ \mathrm{mL}, 7 \mathrm{had}>200 \mathrm{CD} 4$ cells $/ \mathrm{mm}^{3}$. Of these 7,5 were asymptomatic and would not require primary prophylaxis against opportunistic infections by current guidelines. Only 
Figure 2. Kaplan-Meier curves show survival (A) and survival free of clinical progression (B) by baseline HIV RNA tertile (lowest, solid line, 2.49-4.91 log copies/mL; middle, long dashes, 4.94-5.74; highest, short dashes, 5.75-6.97).
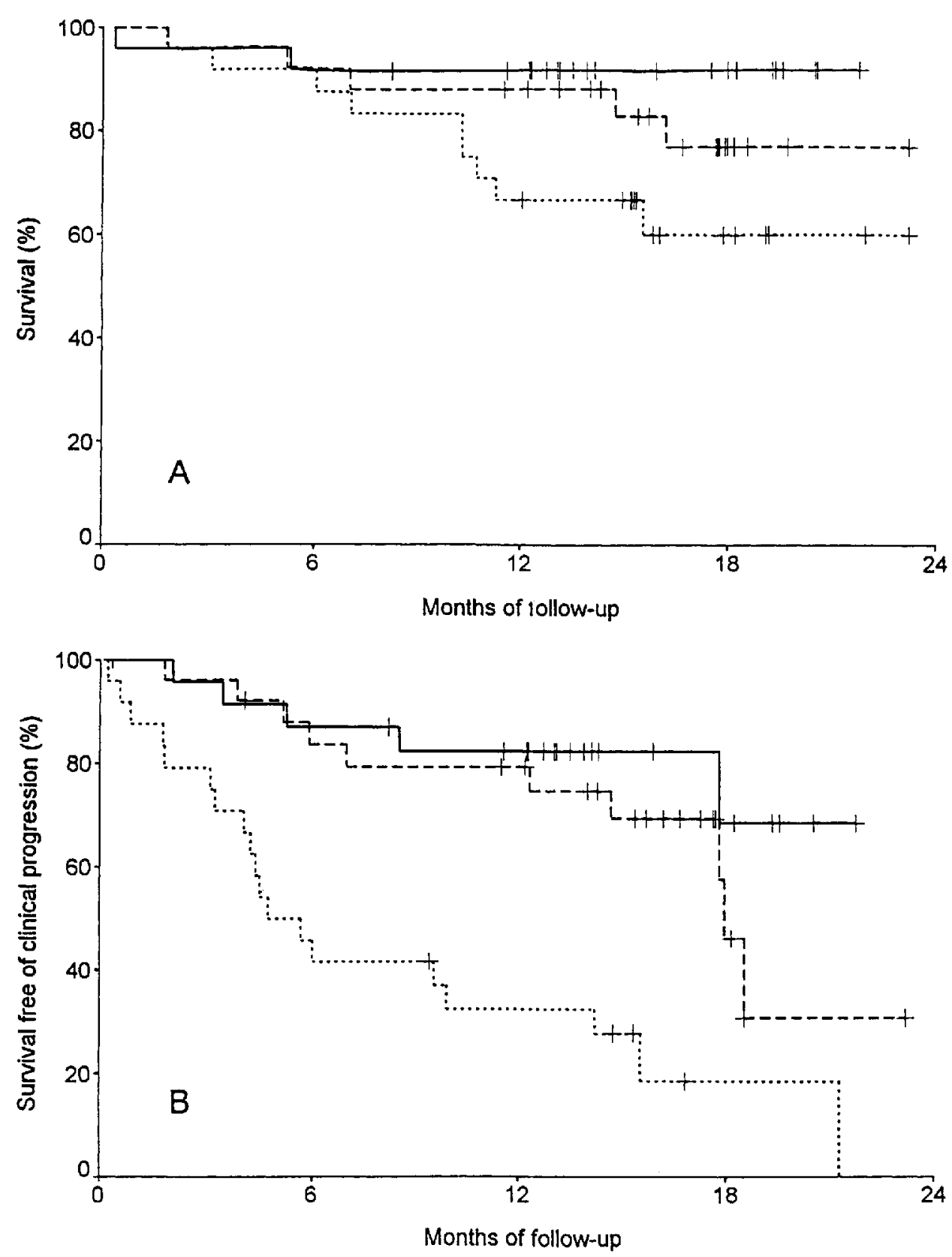

1 received prophylaxis against $P$. carinii pneumonia. During follow-up, 4 of the 5 patients developed new opportunistic infections. The clinical benefit of various therapeutic and prophylactic interventions in patients with high circulating levels of HIV RNA should be evaluated in randomized trials.

HIV RNA level was determined using an in-house assay; lower levels might be measured using commercial assays. In this context, the HIV RNA levels reported here should not be considered absolute values but rather as supporting the concept that patients with high HIV RNA values have an increased risk of developing opportunistic infections.

This study included a selected patient population infected before 1986 and alive in 1993. Of persons infected before 1986 ,
$49 \%$ died before this study began (data not shown). Patients in our study represented a full spectrum of HIV disease (by CDC classification) and did not differ markedly from the patient population in the Swiss HIV Cohort Study [11]. This suggests that the present results might be extended to the general HIV-infected population. These data are also in agreement with two recent studies on seroconverters followed several years, which showed that viremia level predicted clinical outcome $[15,16]$.

The different predictive values of CD4 cell counts and HIV RNA levels may be related to methodologic issues or to different pathogenic mechanisms. The inability of HIV RNA levels to predict mortality after CD4 cell counts have been taken into 
Table 2. Relative hazards of death by HIV RNA level, clinical stage of HIV disease, and CD4 cell count at baseline in 73 patients infected with HIV for $7-11$ years.

\begin{tabular}{|c|c|c|c|c|}
\hline & \multicolumn{2}{|c|}{ Univariate analysis } & \multicolumn{2}{|c|}{ Multivariate analysis } \\
\hline & $\mathrm{RH}(95 \% \mathrm{CI})$ & $P^{*}$ & $\mathrm{RH}(95 \% \mathrm{CI})$ & $P$ \\
\hline HIV RNA tertile & & .10 & & .81 \\
\hline Lowest & 1.0 & & 1.0 & \\
\hline Middle & $2.3(0.4-11.6)$ & & $1.7(0.3-8.8)$ & \\
\hline Highest & $4.7(1.0-21.9)$ & & $1.6(0.3-8.0)$ & \\
\hline Clinical stage & & .001 & & .67 \\
\hline A & 1.0 & & 1.0 & \\
\hline B & $3.8(0.4-32.5)$ & & $1.0(0.1-8.6)$ & \\
\hline $\mathrm{C}$ & $13.7(1.8-107.4)$ & & $1.5(0.2-13.9)$ & \\
\hline \multicolumn{5}{|l|}{ CD4 cell count (continuous)/ } \\
\hline decrease of 100 cells $/ \mathrm{mm}^{3}$ & $4.0(1.8-9.0)$ & $<.001$ & $3.5(1.5-8.2)$ & .003 \\
\hline
\end{tabular}

NOTE. RH, relative hazard; $\mathrm{CI}$, confidence interval.

* Based on Wald statistic for all levels of variable.

account may simply be due to overadjustment. If an increase in HIV RNA level is the main cause of CD4 depletion [5, 6], which in turn leads to death, then adjustment for the intervening variable (CD4 cell count) would erase the association between the primary cause (HIV RNA) and the outcome of interest (death). On the other hand, active viral replication might increase the occurrence of opportunistic infections through mechanisms that do not necessarily involve CD4 cell depletion. One such mechanism might be activation of latent or chronic viral infections. Activation of HIV replication occurs both in vitro and in vivo. Infection by herpes group viruses and by the hepatitis B virus activates HIV replication [17-21]. The reverse might also be true; that is, increased HIV replication may activate other latent infections. Another mechanism might be a virus-induced destruction of monocytes and macrophages that might facilitate the spread of superinfections by intracellular parasites $[22,23]$. Finally, the small study sample (only 14 deaths attributed to HIV infection) might have precluded the finding of a direct relationship between RNA level and mortality, which might be found in studies with larger patient populations.

In conclusion, our data highlight the value of HIV RNA level as an independent predictor of disease progression. Routine measurement of circulating levels of HIV RNA may identify patients at high risk of opportunistic infections who do not currently qualify for antiretroviral therapy or for preventive treatment of opportunistic infections on the basis of their CD4 cell counts. These patients should be considered for early therapeutic intervention.

\section{Swiss HIV Cohort Study Group Members}

Study group members are M. Battegay, P. Bürgisser, R. Doorly, M. Egger, P. Erb, W. Fierz, M. Flepp, P. Francioli, P. Grob, U.

Table 3. Relative hazards of clinical progression by HIV RNA level, clinical stage of HIV disease, and CD4 cell count at baseline in 73 patients infected with HIV for $7-11$ years.

\begin{tabular}{|c|c|c|c|c|}
\hline & \multicolumn{2}{|c|}{ Univariate analysis } & \multicolumn{2}{|c|}{ Multivariate analysis } \\
\hline & $\mathrm{RH}(95 \%) \mathrm{CI})$ & $P^{*}$ & $\mathrm{RH}(95 \% \mathrm{CI})$ & $P^{*}$ \\
\hline HIV RNA tertile & & $<.001$ & & $<.001$ \\
\hline Lowest & 1.0 & & 1.0 & \\
\hline Middle & $1.8(0.6-5.4)$ & & $1.8(0.6-5.4)$ & \\
\hline Highest & $6.4(2.3-17.3)$ & & $6.1(2.1-17.9)$ & \\
\hline Clinical stage & & .09 & & .36 \\
\hline A & 1.0 & & 1.0 & \\
\hline $\mathrm{B}$ & $1.2(0.5-3.1)$ & & $0.5(0.2-1.5)$ & \\
\hline $\mathrm{C}$ & $2.4(1.0-6.0)$ & & $0.9(0.3-2.4)$ & \\
\hline \multicolumn{5}{|l|}{ CD4 cell counts (continuous) $/$} \\
\hline decrease of 100 cells $/ \mathrm{mm}^{3}$ & $1.3(1.1-1.6)$ & .005 & $1.2(1.0-1.5)$ & .09 \\
\hline
\end{tabular}

NOTE. RH, relative hazard; $\mathrm{CI}$, confidence interval.

* Based on Wald statistic for all levels of variable. 
Grüninger, B. Hirschel, B. Ledergerber, R. Lüthy, R. Malinverni, L. Matter, M. Opravil, F. Paccaud, L. Perrin, W. Pichler, M. Rickenbach, O. Rutschmann, P. Vernazza, and J, von Overbeck.

\section{Acknowledgments}

We thank the patients for participating in the study and AIDS Center medical staff and private physicians in the Geneva area, especially J.-F. Balavoine, C. Berret, J. de Haller, C. Junet, J. Lederrey, and $J$. Wintsch, for providing patient clinical data and blood samples.

\section{References}

1. Turner BJ, Hecht FM, Ismail RB. CD4 ${ }^{+}$T-lymphocyte measures in the treatment of individuals infected with human immunodeficiency virus type 1. Arch Intern Med 1994; 154:1561-73.

2. Taylor JM, Fahey Jl, Detels R, Giorgi JV. CD4 percentage, CD4 number, and $\mathrm{CD} 4: \mathrm{CD} 8$ ratio in HIV infection: which to choose and how to use. J Acquir Immune Defic Syndr 1989;2:114-24.

3. Tsoukas CM, Bernard NF. Markers predicting progression of human immunodeficiency virus-related disease. Clin Microbiol Rev 1994;7: $14-28$.

4. Fahey JL, Taylor JMG, Detels R, et al. The prognostic value of cellular and serologic markers in infection with human immunodeficiency virus type 1. N Engl J Med 1990;322:166-72.

5. Wei X, Ghosh SK, Taylor ME, et al. Viral dynamics in human immunodeficiency virus type 1 infection. Nature 1995;373:117-22.

6. Ho DD, Neumann AU, Perelson AS, Chen W, Leonard JM, Markowitz. M. Rapid turnover of plasma virions and CD4 lymphocytes in HIV-1 infection. Nature 1995;373:123-6.

7. Concorde Coordinating Committee. Concorde: MRC/ARNS randomised double-blind controlled trial of immediate and deferred zidovudine in symptom-free HIV infection. Lancet 1994;343:871-81.

8. Yerly S, Chamot E, Hirschel B, Perrin L. Quantitation of human immunodeficiency virus provirus and circulating virus: relationship with immunologic parameters. J Infect Dis 1992; 166:269-76.

9. Lafeuillade A, Tamalet C, Pellegrino P, De Micco P, Vignoli C, Quilichini R. Correlation between surrogate markers, viral load, and disease progression in HIV-1 infection. J Acquir Immune Defic Syndr 1994; 7 : $1028-33$.
10. Verhofstede C, Renier S, Van Wanzeele F, Plum J. Evaluation of proviral copy number and plasma RNA as early indicators of progression in HIV1 infection: correlation with virological and immunological markers of disease. AIDS 1994;8:1421 -7.

11. Ledergerber B, von Overbeck J, Egger M, Lüthy R, Swiss HIV Cohort Study. The Swiss HIV Cohort Study: rationale, organization, and selected baseline characteristics. Soz Praventivmed 1994;39:387-94.

12. Centers for Disease Control and Prevention. 1993 revised classification system for HIV infection and expanded surveillance case definition for AIDS among adolescents and adults. MMWR Morb Mortal Wkly Rep 1993; 41(RR-17)17:1-19.

13. Baumberger C, Kinloch de-Loës S, Yerly S, et al. High level of circulating RNA in patients with symptomatic HIV-1 infection. AIDS 1993; 7(suppl 2):59-64.

14. Lee ET. Statistical methods for survival data analysis. 2nd ed. New York: John Wiley \& Sons, 1992.

15. Mellors JW, Kingsley LA, Rinaldo CR, et al. Quantitation of HIV-1 RNA in plasma predicts outcome after seroconversion. Ann Intern Med 1995; 122:573-9.

16. Henrard DR, Phillips JF, Muenz LR, et al. Natural history of HIV-1 cellfree viremia. JAMA 1995;274:554-8.

17. Paya $\mathrm{CV}$, Virelizier $\mathbb{L}$, Michelson S. Modulation of T-cell activation through protein kinase $\mathrm{C}$ - or A-dependent signalling pathways synergistically increases human immunodeficiency virus long terminal repeat induction by cytomegalovirus immediate-early proteins. J Virol 1991; 65:5477-84.

18. Castro BA, Homsy J, Lennette E, Murthy KK, Eichberg JW, Levy JA. HIV-1 expression in chimpanzee can be activated by CD8 ${ }^{+}$cell depletion or CMV infection. Clin Immunol Immunopathol 1992;65:227-33.

19. Fiala M, Cone LA, Christopher R, Kermani V, Gombein JA. Human immunodeficiency virus type 1 antigenaemia is enhanced in patients with disseminated cytomegalovirus infection and deficient $T$ lymphocytes. Res Immunol 1991;142:815-9.

20. Knox KK, Carrigan DR. Disseminated active HHV-6 infections in patients with AIDS. Lancet 1994;343:555-8.

21. Margolis DM, Rabson AB, Straus SE, Ostrove JM. Transactivation of the HIV-1 LTR by HSV-1 immediate-early genes. Virology 1992;186: $788-91$.

22. Wehle K, Schirmer M, Dunnebacke-Hinz J, Kupper T, Pfitzer P. Quantitive differences in phagocytosis and degradation of Pneumocystis carinii by alveolar macrophages in AIDS and non-HIV patients in vivo. Cytopathology 1993; 4:231-6.

23. Chaturvedi S, Frame P, Newman SL. Macrophages from human immunodeficiency virus-positive persons are defective in host defense against Histoplasma capsulatum. J Infect Dis 1995; 171:320-7. 